\title{
Homocysteine Exposure Impairs Myocardial Resistance to Ischaemia Reperfusion and Oxidative Stress
}

\author{
Amer Almashhadany ${ }^{a}$ Dareuosh Shackebaei ${ }^{b}$ Thomas Van der Touw ${ }^{a}$ \\ Graham L. Jones ${ }^{\mathrm{a}}$ M. - Saadeh Suleiman ${ }^{\mathrm{C}}$ Nicola King ${ }^{\mathrm{d}}$
}

aSchool of Science and Technology, McClymont Building, University of New England, Armidale, Australia; 'Medical Biology Research Centre, Kermanshah University of Medical Sciences, Kermanshah, Iran; 'Bristol Heart Institute, School of Clinical Sciences, University of Bristol, Bristol Royal Infirmary, Bristol, UK; ${ }^{\mathrm{d} S}$ School of Biomedical and Healthcare Sciences, Plymouth University Peninsula Schools of Medicine and Dentistry, Plymouth University, Plymouth, UK

\section{Key Words}

Hyperhomocysteinemia $\bullet$ Ischemia reperfusion • Oxidative stress $•$ Cardiomyocytes

\begin{abstract}
Background/Aims: Hyperhomocysteinaemia is recognised as a strong independent risk factor for developing cardiovascular disease. This study investigated how an acute homocysteine dose affected cardiac performance during ischaemia reperfusion and cardiomyocyte contractility and morphology under normal conditions and during oxidative stress. Methods: Cardiac function was measured in isolated and perfused rat hearts before and after 40 minutes' global normothermic ischaemia. Where used, $0.1 \mathrm{mM} \mathrm{L}$-homocysteine was present prior to, and throughout ischaemia, before wash out after 10 minutes' reperfusion. Calcium transients under normal conditions and changes in contractile synchronicity during oxidative stress (exposure to $0.2 \mathrm{mM} \mathrm{H}_{2} \mathrm{O}_{2}$ ) were measured in freshly isolated rat cardiomyocytes incubated for 60 minutes $\pm 0.1 \mathrm{mM}$ L-homocysteine. Results: During ischaemia reperfusion $0.1 \mathrm{mM}$ L-homocysteine significantly reduced the rate pressure product during reperfusion $(10,038 \pm 749$ vs. 5955 $\pm 567 \mathrm{mmHg} b p m, \mathrm{p}<0.001$ ), but did not affect time to ischaemic contracture. Incubation of freshly isolated cardiomyocytes with $0.1 \mathrm{mM}$ L-homocysteine significantly decreased the amplitude of the calcium transient and slowed the time to half relaxation. Conclusions: These findings suggest that homocysteine exposure affected myocardial recovery from ischaemia and contractile homeostasis although the exact mechanisms for these changes remain to be determined.

\section{Introduction}

Cardiovascular disease is the leading cause of death worldwide (WHO 2010). In addition to traditional risk factors such as smoking, hypertension and hyperlipidaemia, newer ones

Dr. Nicola King

KARGER 125
School of Biomedical and Healthcare Sciences, Plymouth University Peninsula Schools of Medicine and Dentistry, Plymouth University, Plymouth, (UK)

Tel. +44 (0)1752 584969, Fax +44 (0)1752 586788, E-Mail Nicola.king@plymouth.ac.uk 


\section{Cellular Physiology Cell Physiol Biochem 2015;37:2265-2274 \begin{tabular}{l|l|l} 
DOI: 10.1159/000438582 & (c) 2015 The Author(s). Published by S. Karger AG, Basel \\
www.karger.com/cpb
\end{tabular} \\ Almashhadany et al.: Homocysteine Impairs Stressed Myocardium}

including sedentary behaviour and a raised plasma concentration of homocysteine (called hyperhomocysteinaemia, HHcy) have been identified [1-3]. L-homocysteine (Hcy) is traditionally thought of as a non-proteinogenic amino acid that is involved in methionine metabolism. Thenormalfasting plasmaconcentration ofHcyis approximately $10 \mu \mathrm{M}$,risingto 30 $\mathrm{M}$ in mild HHcy, up to $100 \mu \mathrm{M}$ in moderate HHcy and as much as $400 \mu \mathrm{M}$ in severe HHcy [3, 4]. The global incidence of severe HHcy is approximately 1 in every 344,000 births, although frequencies of 1 in 65,000 have been found in Australia and Ireland [5]. The commonest cause of severe HHcy is a deficiency in the enzyme, cystathionine beta synthase, which is often associated with early onset of cardiovascular disease before 30 years of age [5].

The pathogenesis of HHcy is thought to involve increased thrombogenicity, greater oxidative stress, over-regulation of redox sensitive inflammatory pathways, impaired endothelial function, atherogenesis, cardiac remodelling $[5,6]$ and inflammasome formation and activation in podocytes [7]. The majority of studies conducted so far have either concentrated on the efficacy of strategies targeting a reduction in plasma Hcy $[2,8]$ or have used vascular endothelial cells, smooth muscle cells, monocytes [2, 4] or podocytes [7]. In contrast, the effect of Hcy and HHcy on the myocardium and functional contractile cardiomyocytes has been little studied. It is known that at very high doses (from 0.5 to $>1$ $\mathrm{mM}$ ) Hcy causes activation of stress signalling pathways [9] and cellular death by apoptosis and necrosis [9-11], whilst lower doses may cause electrophysiological changes, particularly affecting the action potential [12-14].

If the relationship between HHcy and the risk of developing cardiovascular disease has been well researched, the correlation between HHcy or Hcy and sensitivity to subsequent cardiovascular insults is less clear. Two studies have shown impaired functional recovery following ischaemia reperfusion in transgenic cystathionine beta synthase deficient mice and increased reperfusion damage [15] and oxidant damage in methionine fed rat hearts [16] and increased area at risk in methionine fed mice [17]. Therefore the aim of this study was to specifically investigate the effect of exposing whole hearts and isolated cardiomyocytes to the clinically relevant dose of $0.1 \mathrm{mM} \mathrm{Hcy}$ on functional performance during ischaemia reperfusion and on calcium homeostasis, morphology and viability, and contractile activity under normal conditions and during oxidative stress.

\section{Materials and Methods}

\section{Animals}

Adult male Wistar rats $(300 \pm 5 \mathrm{~g}$, heart weight $1.16 \pm 0.02 \mathrm{~g})$ were used throughout this study. All rats were killed by stunning followed by cervical dislocation. This was followed by dissection of the heart and processing for Langendorff perfusion or isolation of cardiomyocytes. This work was approved by the Universities of Bristol, New England and Kermanshah University of Medical Sciences and conforms with the Guide for the Care and Use of Laboratory Animals published by the United States National Institutes of Health.

\section{Langendorff heart perfusion}

The use of the Langendorff preparation at Kermanshah University of Medical Sciences has been described previously [18]. In brief, the perfusing solution was Kreb's containing (in mM): $118 \mathrm{NaCl}, 25$ $\mathrm{NaHCO}_{3}, 4.8 \mathrm{KCl}, 1.2 \mathrm{KH}_{2} \mathrm{PO}_{4}, 1.2 \mathrm{MgSO}_{4}, 11$ glucose, and $1.2 \mathrm{CaCl}_{2}$. This was delivered at a constant pressure of $65 \mathrm{mmHg}$, maintained at $37^{\circ} \mathrm{C}$, and aerated with $95 \% \mathrm{O}_{2} / 5 \% \mathrm{CO}_{2}$. Following removal of the left atrial appendage, a deflated water filled ultra-thin balloon was inserted into the left ventricle. This balloon was connected via a rigid polyethylene tube to a pressure transducer, which in turn was connected via a PowerLab to a computer for continuous monitoring of cardiac performance. At the beginning of the experiment, the balloon was inflated to impose an initial end diastolic pressure of 1-6 $\mathrm{mmHg}$. After an initial equilibration period of 60 minutes, the pump was switched off and the heart immersed in solution at $37^{\circ} \mathrm{C}$ to induce 40 minutes of global normothermic ischaemia. Reperfusion was initiated by restarting the pump and was continued for 45 minutes. Where used, 0.05-0.5 mM Hcy was added to the perfusate at the beginning of 


\section{Cellular Physiology Cell Physiol Biochem 2015;37:2265-2274 \begin{tabular}{l|l|l} 
DOI: 10.1159/000438582 & (c) 2015 The Author(s). Published by S. Karger AG, Basel \\
www.karger.com/cpb
\end{tabular} \\ Almashhadany et al.: Homocysteine Impairs Stressed Myocardium}

equilibration or 40 minutes into the equilibration period; was present throughout ischaemia, and for the first 10 minutes of reperfusion.

The level of reperfusion injury was assessed from the release of lactate dehydrogenase (LDH) as described previously [19]. This was achieved by collecting the coronary effluent during the first ten minutes of reperfusion. The samples were measured using a Cell Cytotoxicity kit (LDH) (Roche) using known quantities of LDH (SIGMA) as a standard. Data were calculated by averaging the LDH concentration (IU/ml) in all of the samples for each heart and correcting for body weight.

Isolation of ventricular cardiomyocytes

Calcium tolerant ventricular cardiomyocytes were isolated by enzyme digestion and mechanical dispersion at the Bristol Heart Institute and the University of New England using previously described methods [20,21]. Isolations were then divided into two groups. The cells in one group were incubated with $0.1 \mathrm{mM} \mathrm{Hcy} \mathrm{in} \mathrm{a} \mathrm{gently} \mathrm{shaking} \mathrm{water} \mathrm{bath} \mathrm{at} 37^{\circ} \mathrm{C}$ for 60 minutes, whilst cells in the other group were incubated under identical conditions without Hcy (control).

Loading with Fura-2AM and Measurement of calcium transients

Intracellular calcium transients were measured using Fura-2AM. The cells were loaded with the dye according to procedures that we have described previously [20]. In brief on the morning of the experiment a stock solution containing $1 \mathrm{mM}$ Fura-2AM was prepared in dimethyl sulphoxide (DMSO). Following incubation with/without $0.1 \mathrm{mM}$ Hcy the cell suspension continued to be incubated under the same conditions for a further 15 minutes with sufficient of the Fura-2AM to give a final concentration of $2 \mu \mathrm{M}$. The suspension was then centrifuged and the resulting cell pellet suspended in fresh dye free Tyrode containing (in mM): $137 \mathrm{NaCl}, 5 \mathrm{KCl}, 1.2 \mathrm{MgSO}_{4}, 1.2 \mathrm{NaH}_{2} \mathrm{PO}_{4}, 16$ glucose, $1 \mathrm{CaCl}_{2}$ and $20 \mathrm{HEPES}$ (pH 7.4 with $\mathrm{NaOH}$ ).

Fluorescence levels in dye loaded cardiomyocytes were measured using a photon counting system (Newcastle Photometric Systems [Newcastle UK]) that was attached to an inverted Nikon Diaphot microscope (Nikon, Surrey UK). Calcium measurements using Fura-2 were calculated from fluorescence ratios with excitation at $340 \mathrm{~nm}$ and emission at $510 \mathrm{~nm}$ versus excitation at $380 \mathrm{~nm}$ and emission at 510 $\mathrm{nm}[20]$.

Effect of Hcy and oxidative stress on cellular contraction

Cells were superfused in a chamber on the stage of the inverted fluorescence microscope at $37^{\circ} \mathrm{C}$ and field stimulated at $0.2 \mathrm{~Hz}$. Cell contraction was visualised via a video camera and monitor as described previously $[20,21]$. The best field of cells, which were rod shaped and contracting synchronously in response to stimulation with no spontaneous contractions was selected. All experiments began with the cells superfused with normal Tyrode (as described above). After a short period of equilibration oxidative stress was induced by switching the superfusing media to an identical Tyrode containing $0.2 \mathrm{mM} \mathrm{H}_{2} \mathrm{O}_{2}$ [20, 21]. The $\mathrm{H}_{2} \mathrm{O}_{2}$ superfusion continued until all the cells in the field under observation displayed asynchronous behaviour in response to the field stimulation when the experiment was terminated.

Effect of Hcy with/without oxidative stress on cell morphology and viability

Oxidative stress leading to necrosis and apoptosis is known to be involved in the pathogenesis of ischaemia reperfusion. These effects can be mimicked in isolated cardiomyocytes through treatment with $\mathrm{H}_{2} \mathrm{O}_{2}$ [22]. We have also shown that exposure to $0.2 \mathrm{mM} \mathrm{H}_{2} \mathrm{O}_{2}$ is a good model for inducing oxidative stress in isolated cardiomyocytes, which is marked by changes to contractile activity and the intracellular generation of hydroxyl radicals $[20,21]$. Therefore in order to study the effects of an oxidant insult, in a separate series of experiments, cells were incubated with/without $0.1 \mathrm{mM} \mathrm{Hcy}$ with/without $0.2 \mathrm{mM} \mathrm{H}_{2} \mathrm{O}_{2}$ at $37^{\circ} \mathrm{C}$ in a gently shaking water bath for 210 minutes. At timed intervals a drop of the cell suspension was placed onto the slide of a light microscope and $0.4 \%$ Trypan Blue added (see Fig. 1). A field of cells was randomly selected and a calculation made of the percentages of rod shaped cells and percentage of hypercontracted cells containing Trypan Blue.

Data analysis

Data are presented as means \pm SEM. Comparisons between datasets were made using student's T-test or ANOVA with a Tukey-Kramer post-test. 

the time points of $\mathrm{Hcy}$ and $\mathrm{H}_{2} \mathrm{O}_{2}$
Fig. 1. Study protocol indicating application.

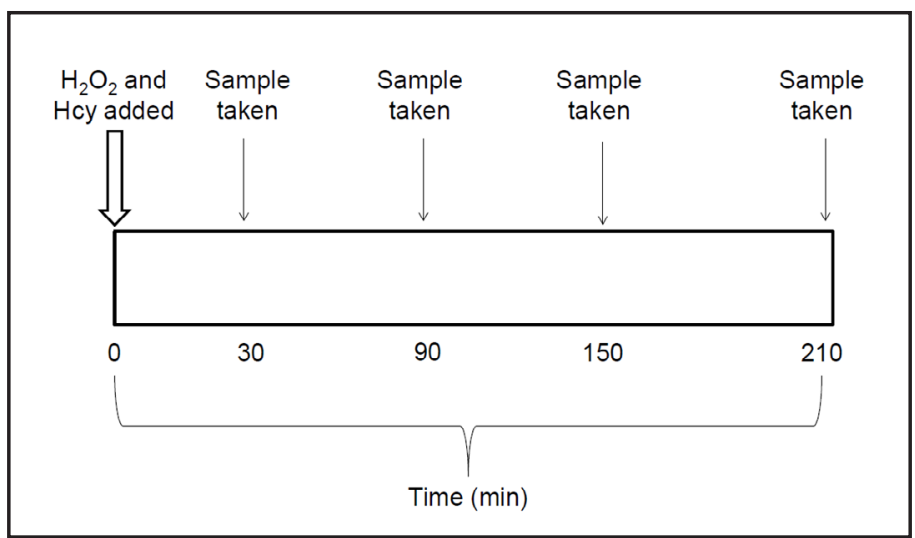

Fig. 2. Effect of homocysteine on the recovery of contractile activity during ischaemia-reperfusion. Shown here is the (a) left ventricular developed pressure (LVDP) and (b) heart rate (HR) at the end of 60 minutes pre-ischaemic perfusion \pm 0.1 $\mathrm{mM}$ L-homocysteine and at the end of 45 minutes reperfusion following a period of 40 minutes global normothermic ischaemia. + $0.1 \mathrm{mM}$ homocysteine labelled Hcy; Solid bars: pre-ischaemia; open bars: reperfusion. ${ }^{*} \mathrm{p}<0.05$ vs. control; ${ }^{* *} \mathrm{p}<0.01$ vs. pre-ischaemia. Data shown are the means \pm SEM of $n=13$ hearts for control and $n=5$ for Hcy. (c) Effect of homocysteine on the functional performance of isolated and perfused hearts prior to and after exposure to global normothermic ischaemia. Shown here is the rate pressure product at the end of 60 minutes' perfusion $\pm 0.1 \mathrm{mM} \mathrm{Hcy}$ and at the end of 45 minutes' reperfusion following 40 minutes global normothermic ischaemia. Solid bars: rate pressure product pre-ischaemia; open bars: rate pressure product at the end of reperfusion. $\dagger \mathrm{p}<0.001$ vs. pre-ischaemia; $\neq \mathrm{p}<0.001$ vs. the reperfusion rate pressure product in controls. Data shown are the means \pm SEM of $n=13$ hearts for control and $n=5$ for Hcy.

\section{Results}

Isolated rat hearts were perfused with (Hcy) or without (control) $0.1 \mathrm{mM} \mathrm{Hcy} \mathrm{for}$ 60 minutes prior to exposure to 40 minutes of global normothermic ischaemia and 45 minutes reperfusion. Figure 2 shows the left ventricular developed pressure $(2 \mathrm{a})$ and heart rate $(2 \mathrm{~b})$ in these hearts pre-ischaemia and at the end of reperfusion. The presence of Hcy caused a significant reduction in the recovery of left ventricular developed pressure compared to control (Fig. 2a), but did not affect the recovery of heart rate $(2 \mathrm{~b})$.

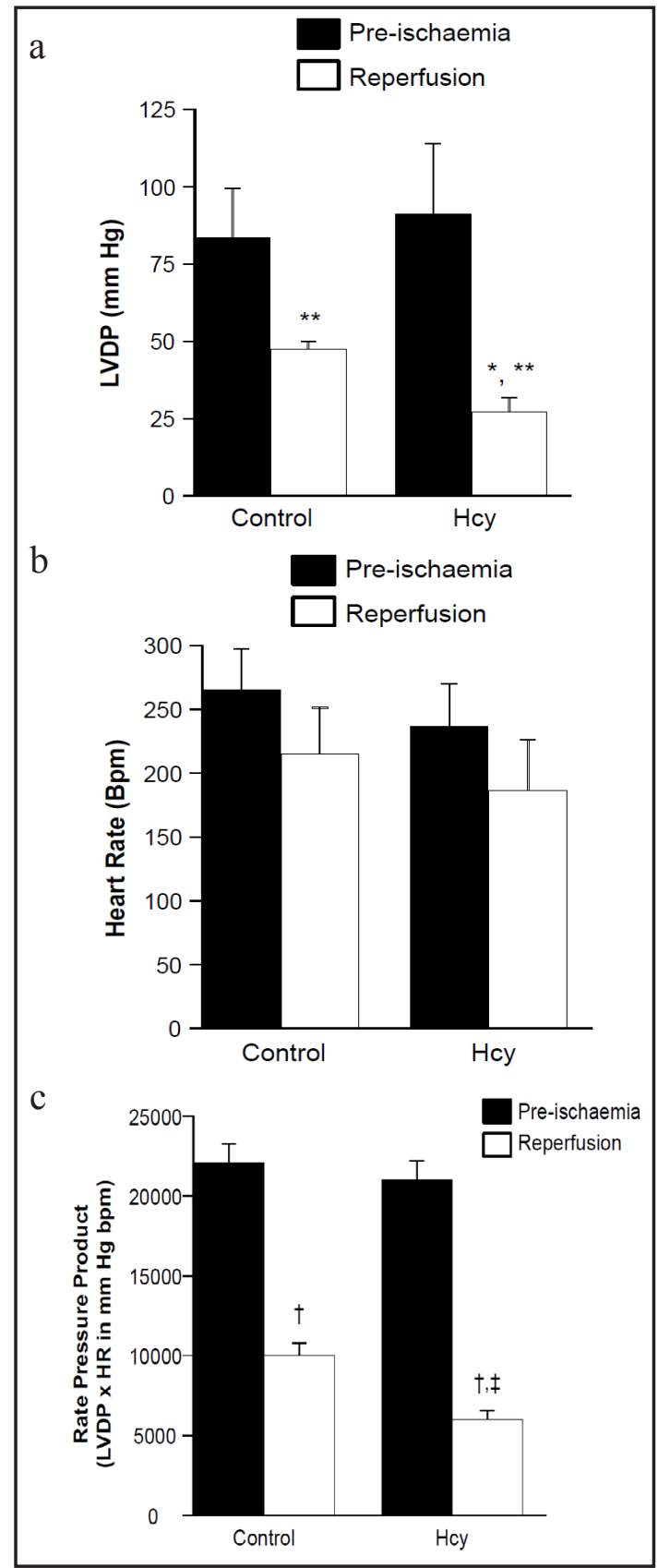


Fig. 3. Effect of homocysteine on myocardial characteristics during ischaemia and reperfusion damage. Shown here is the (a) time to ischaemic contracture and (b) release of lactate dehydrogenase (LDH) for hearts perfused $\pm 0.1 \mathrm{mM}$ Hcy prior to 40 minutes ischaemia and 30 minutes reperfusion. Solid bars: control; open bars: +0.1 mM Hcy. Data shown are the means \pm SEM of $n=$ 13 hearts for control and $\mathrm{n}=5$ for Hcy.

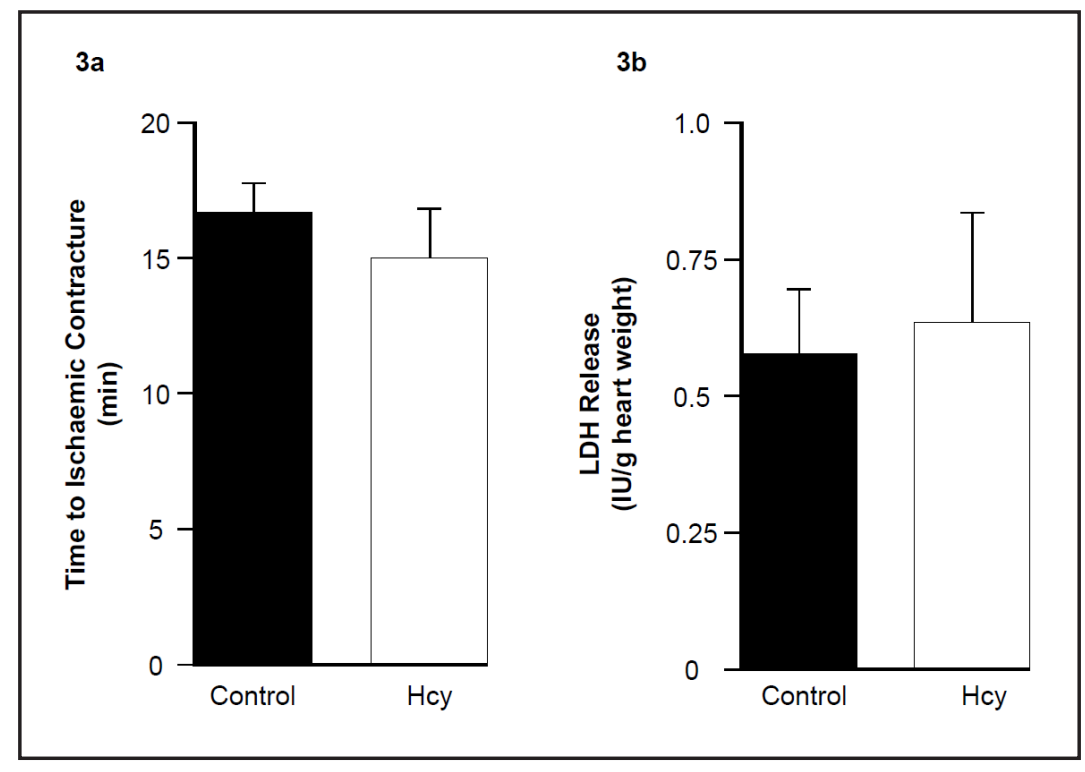

The effect of Hcy on the rate pressure product (RPP, left ventricular developed pressure in $\mathrm{mm} \mathrm{Hg}$ multiplied by heart rate in bpm) before and after ischaemia is shown in Fig. 2c. Under normal conditions pre-ischaemia, the RPP was not affected by 60 minutes of perfusion with $0.1 \mathrm{mM} \mathrm{Hcy}$. Following 40 minutes of global normothermic ischaemia, there was a significant reduction in the RPP in both the control and the homocysteine group, however the RPP at the end of reperfusion for the hearts perfused with $0.1 \mathrm{mM}$ homocysteine was significantly worse than that of the control group.

Figure 3 shows the effect of Hcy on myocardial changes during ischaemia and on reperfusion damage. The time taken for the hearts to undergo ischaemic contracture (Fig. $3 \mathrm{a}$ ), and the concentration of lactate dehydrogenase released during the first ten minutes of reperfusion (Fig. $3 \mathrm{~b}$ ) were not affected by the presence of $0.1 \mathrm{mM}$ Hcy.

The mean coronary flow pre-ischaemia in control was $13.1 \pm 0.96 \mathrm{ml} / \mathrm{min}$ compared to $12.1 \pm 0.81 \mathrm{ml} / \mathrm{min}$ in hearts perfused with Hcy. There is no significant difference between these values. Upon reperfusion the coronary flow in the controls was $6.4 \mathrm{ml} / \mathrm{min}$ which was significantly less than the pre-ischaemic value. The reperfusion value in the Hcy perfused hearts was $6.3 \pm 0.2 \mathrm{ml} / \mathrm{min}$. This value was not significantly different from the coronary flow in the control upon reperfusion.

Cardiac parameters measured before and after ischaemia including: the recovery of left ventricular developed pressure and heart rate; the rate pressure product; ischaemic contracture and the release of lactate dehydrogenase were not significantly altered by shortening the period of exposure to $0.1 \mathrm{mM}$ Hcy to 20 minutes prior to ischaemia; or by reducing the concentration of Hcy perfused for 60 minutes prior to ischaemia to $0.05 \mathrm{mM}$ (data not shown). In contrast the presence of $0.5 \mathrm{mM}$ Hcy significantly worsened the recovery of the rate pressure product compared to control and compared to that seen with $0.1 \mathrm{mM}$ homocysteine (data not shown).

In order to investigate the hypothesis that exposure to $0.1 \mathrm{mM}$ Hcy was disruptive to the myocardium's ionic homeostasis three further experiments were conducted. In the first of these (as shown in Fig. 4) calcium transients were measured in isolated cardiomyocytes that had been incubated for 60 minutes with/without $0.1 \mathrm{mM}$ Hcy. Figure $4 \mathrm{a}$ and $4 \mathrm{~b}$ show exemplar traces for the $\mathrm{Ca}^{2+}$ transient under control conditions (4a) and in the presence of homocysteine (4b). As shown in Fig. 4c the amplitude of the $\mathrm{Ca}^{2+}$ transient was significantly greater under control conditions compared to the $\mathrm{Ca}^{2+}$ transient in cardiomyocytes exposed to homocysteine $(\mathrm{p}<0.05)$. Figure $4 \mathrm{~d}$ shows that the time to half decay of the $\mathrm{Ca}^{2+}$ transient was significantly reduced in cardiomyocytes exposed to $0.1 \mathrm{mM}$ homocysteine compared to control $(\mathrm{p}<0.03)$ indicating a faster rate of decline of the calcium transient.

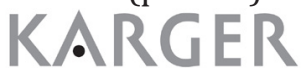




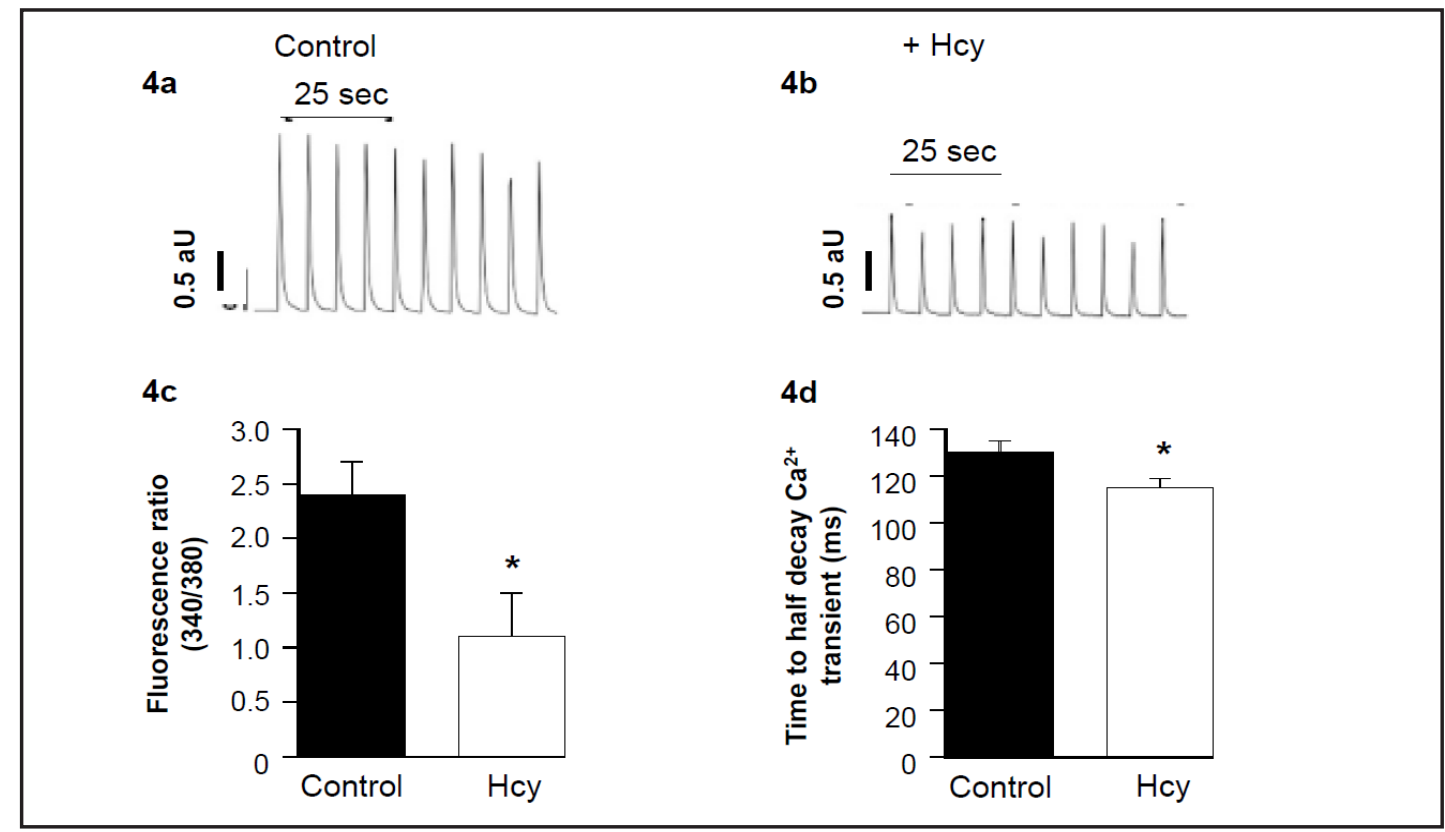

Fig. 4. Effect of homocysteine on the calcium transient measured in freshly isolated cardiomyocytes under normal conditions. (4a) Example trace showing the $\mathrm{Ca}^{2+}$ transient measured under control conditions using Fura-2. A.u. arbitrary units. (4b) Example trace showing the $\mathrm{Ca}^{2+}$ transient measured in cardiomyocytes exposed to $0.1 \mathrm{mM}$ Hcy using Fura-2. (4c) Mean amplitude of the $\mathrm{Ca}^{2+}$ transient measured under control conditions and after exposure to $0.1 \mathrm{mM}$ homocysteine. Solid bars: control; open bars $+0.1 \mathrm{mM} \mathrm{Hcy.}{ }^{*} \mathrm{p}<$ 0.05 vs. control. Data shown are the means \pm SEM for $n=10$ cells from 3 separate isolations. ( $4 \mathrm{~d}$ ) time taken for half the $\mathrm{Ca}^{2+}$ transient to decay in control cardiomyocytes and those exposed to $0.1 \mathrm{mM} \mathrm{Hcy.}{ }^{*} \mathrm{p}<0.05$ vs. control. Other details as Fig. 4c.

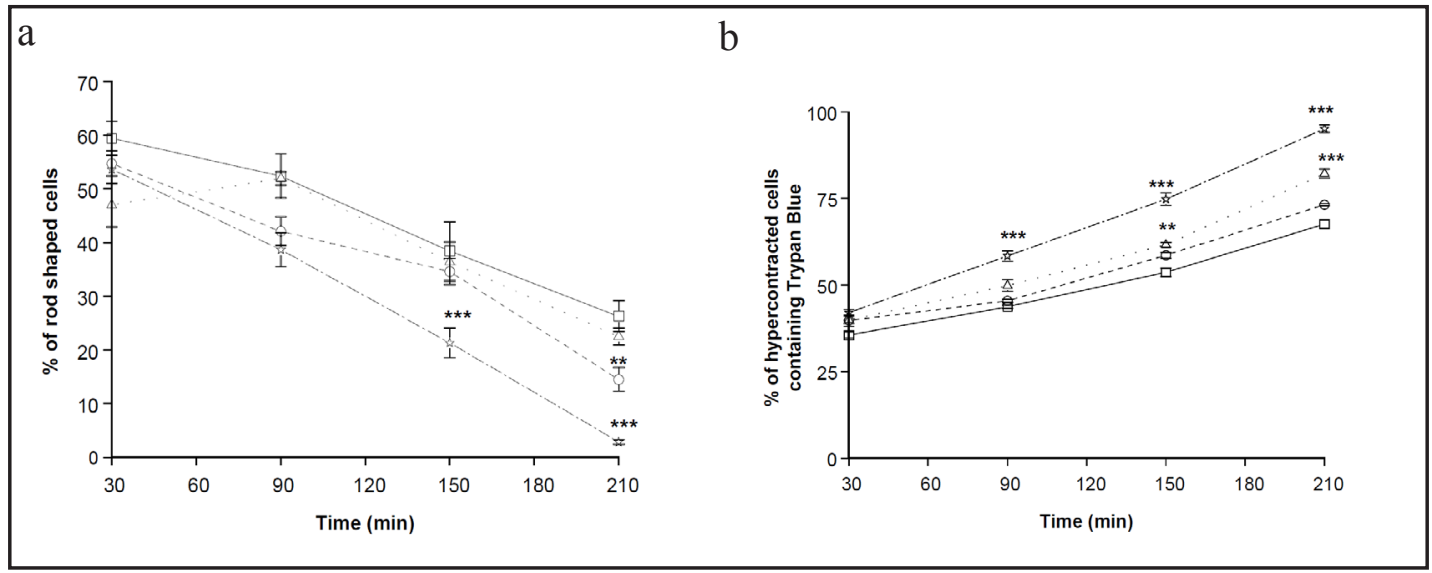

Fig. 5. Effect of incubation with homocysteine and/or $\mathrm{H}_{2} \mathrm{O}_{2}$ on cell morphology and viability. (5a) Percentage of rod shaped cells counted at timed intervals in the presence of no additives (control), $0.2 \mathrm{mM} \mathrm{H}_{2} \mathrm{O}_{2}, 0.1$ $\mathrm{mM} \mathrm{Hcy}$, and $0.1 \mathrm{mM} \mathrm{Hcy}$ and $0.2 \mathrm{mM} \mathrm{H}_{2} \mathrm{O}_{2}$. Control: squares, solid line; $+\mathrm{H}_{2} \mathrm{O}_{2}$ : circles, dashed line; $+\mathrm{Hcy}$ : triangles, dotted line; and $+\mathrm{H}_{2} \mathrm{O}_{2}$ and Hcy: stars, dash-dotted line. ${ }^{* *} \mathrm{p}<0.01$ vs. control at 210 minutes, *** $\mathrm{p}<0.001$ vs. control at 210 minutes. Data shown are mean \pm SEM from four separate isolations. (5b) Percentage of hypercontracted cells containing Trypan Blue counted at timed intervals. All other details as for Fig. 5a.

We have previously shown that exposure to $0.2 \mathrm{mM} \mathrm{H}_{2} \mathrm{O}_{2}$ is a good model for inducing oxidative stress in isolated cardiomyocytes, which is marked by changes to contractile activity and the intracellular generation of hydroxyl radicals [20,21]. Therefore in the second 


\section{Cellular Physiology Cell Physiol Biochem 2015;37:2265-2274 and Biochemistry Published online: December 02, 2015 le $\begin{aligned} & \text { DOI: } 2015 \text { The Author(s). Published by S. Karger AG, Basel } \\ & \text { www.karger.com/cpb }\end{aligned}$ \\ Almashhadany et al.: Homocysteine Impairs Stressed Myocardium}

Fig. 6. Effect of homocysteine on the contractile activity of freshly isolated cardiomyocytes during exposure to oxidative stress. Shown here is the time taken for isolated cardiomyocytes to exhibit asynchronous behaviour in response to stimulation at $0.2 \mathrm{~Hz}$ during superfusion with $0.2 \mathrm{mM} \mathrm{H}_{2} \mathrm{O}_{2}$. Solid bars: control; open bars: $+0.1 \mathrm{mM} \mathrm{Hcy.}{ }^{* *} \mathrm{p}<$ 0.01 vs. control. Data shown are the means \pm SEM of $\mathrm{n}=39$ cells from 3 separate isolations for control and $n=46$ cells from 3 separate isolations for + Hcy.

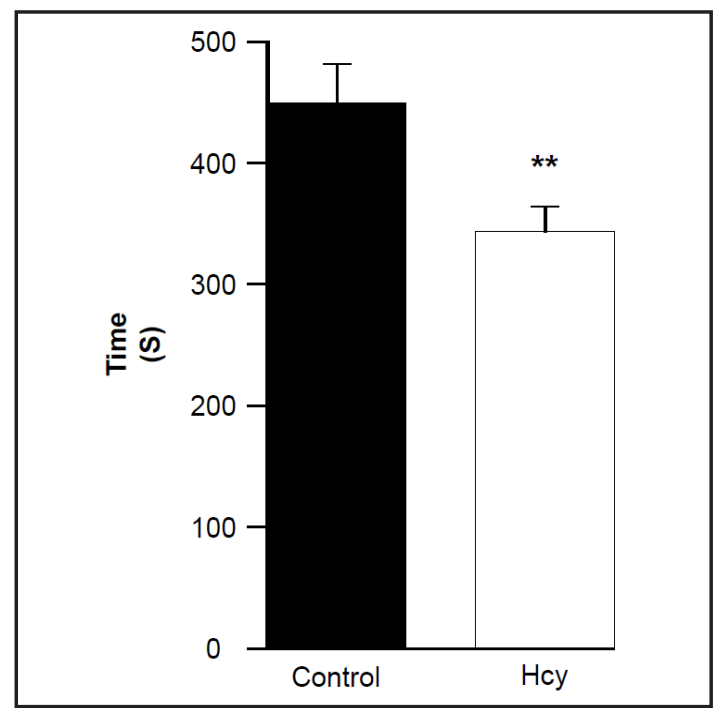

experiment the effect of Hcy exposure with/without oxidative stress on cell morphology and viability was investigated. These results are shown in Fig. $5 \mathrm{a}$ and $5 \mathrm{~b}$. With time the percentage of rod shaped cells decreased and the percentage of hypercontracted cells containing Trypan Blue significantly increased under all conditions. At 90 minutes there was a significant increase in the percentage of hypercontracted cells containing Trypan Blue in the presence of $\mathrm{Hcy}$ and $\mathrm{H}_{2} \mathrm{O}_{2}$ compared to control $(\mathrm{p}<0.001$, Fig. $5 \mathrm{~b})$. By the end of the experiment at 210 minutes the greatest increase had occurred in the presence of $\mathrm{H}_{2} \mathrm{O}_{2}$ and homocysteine followed by $\mathrm{H}_{2} \mathrm{O}_{2}$ (also $\mathrm{p}<0.001$ vs. control) alone, whilst the change in the presence of Hcy only was not significantly different from the control.

The final experiment investigated whether incubation of isolated cardiomyocytes with Hcy affected their contractile behaviour during oxidative stress. The time to dysrhythmia (asynchronous behaviour in response to field stimulation) for freshly isolated cardiomyocytes incubated with or without $0.1 \mathrm{mM}$ Hcy for 60 minutes prior to exposure to $0.2 \mathrm{mM} \mathrm{H}_{2} \mathrm{O}_{2}$ was measured. These results are displayed in Fig. 6. This figure shows that a significantly shorter time elapsed before the Hcy incubated cardiomyocytes displayed asynchronous contractile behaviour compared to the control cells. At the same time there was a mismatch between the calcium transient and contraction.

\section{Discussion}

An increased plasma concentration of Hcy has been recognised as a strong independent risk factor for the development of cardiovascular disease $[2,23]$. This has led to a number of studies exploring the possible mechanisms by which HHcy may impair vascular function $[2,3]$ and the effects of interventions targeting a lowering of the plasma homocysteine concentration [8]. In contrast, surprisingly little work has been carried out investigating the acute effects of Hcy on cardiac performance during ischaemia reperfusion and on calcium homeostasis and the contractile properties of the individual cardiomyocytes during oxidative stress. This may be relevant in the setting of acute metabolic disease. Therefore the aim of this study was to test the hypothesis that Hcy exposure during stressful conditions in the heart would compromise cardiac performance. This indeed appeared to be the case as perfusion of isolated and perfused rat hearts with $0.1 \mathrm{mM}$ Hcy prior to 40 minutes of global normothermic ischaemia and reperfusion led to a significantly impaired recovery of left ventricular developed pressure (Fig. 2a) and a reduction in the rate pressure product (Fig. 2c). In addition, incubation of freshly isolated cardiomyocytes with the same Hcy concentration resulted in a significantly smaller calcium transient under normal conditions, a significantly 


\section{Cellular Physiology Cell Physiol Biochem 2015;37:2265-2274 \\ and Biochemistry Published online: December 02, 2015 le $\begin{aligned} & \text { DOI: } 2015 \text { The Author(s). Published by S. Karger AG, Basel } \\ & \text { www.karger.com/cpb }\end{aligned}$ \\ Almashhadany et al.: Homocysteine Impairs Stressed Myocardium}

faster rate of calcium transient decay (Fig. 4) and a faster loss of contractile synchronicity during exposure to oxidative stress in the presence of $0.2 \mathrm{mM} \mathrm{H}_{2} \mathrm{O}_{2}$ (Fig. 6). Experiments investigating cell morphology and viability showed that cells were most vulnerable in the presence of $\mathrm{H}_{2} \mathrm{O}_{2}$ and Hcy (Fig. 5).

This is the first study to investigate the effects of perfusing normal isolated hearts with Hcy on cardiac functional parameters during ischaemia reperfusion. Previous studies of the effects of homocysteine during ischaemia reperfusion have either investigated transgenic mice [15], or have explored oxidant damage [16] or area at risk [17] in methionine fed animals. The results showed that exposure to $0.1 \mathrm{mM}$ Hcy prior to global normothermic ischaemia impaired recovery of LVDP (Fig. 2a) and RPP (Fig. 2c) but did not adversely affect time to rigor during ischaemia (Fig. 5a) or LDH during reperfusion (Fig. 5b). This correlates well with the lower level of LVDP during reperfusion compared to controls in hearts from transgenic mice where the cystathionine beta synthase gene had been disrupted [15]. In a report that concentrated on the differences between ATP, blood flow and cytosolic adenosine in demand ischaemia vs. coronary occlusion, Hcy perfusion was used as part of the method utilised to measure the adenosine concentration [24]. There was however no comparison with a Hcy free control and therefore little investigation of the effects of Hcy per se [24]. Differences in the experimental procedure, particularly the establishment of HHcy via four weeks of methionine feeding followed by perfusion with normal Hcy free Krebs compared to non-supplemented feeding and pre-ischaemic perfusion with $0.1 \mathrm{mM}$ Hcy may explain the conflicting LDH results between the results in Fig. $3 \mathrm{~b}$ and those of Rohilla and coworkers $[6,16]$. One interesting finding that did however arise out of the investigations by Rohilla and co-workers was the suggestion that HHcy abolished the protective effects of ischaemic pre-conditioning possibly through a mechanism involving activation of protein kinase $\mathrm{C}-\delta$ [16]. A detailed investigation of the effects of pre-ischaemic Hcy perfusion on ischaemic preconditioning was however beyond the scope of this study.

Another significant finding from the studies by Rohilla and co-workers was that HHcy increased oxidative stress during ischaemia reperfusion [16]. This agrees with the findings of Levrand et al. who found that $0.1 \mathrm{mM} \mathrm{Hcy}$ induces cell death in cultured H9C2 cardiomyocytes through the generation of peroxynitrite [9]. It was not surprising therefore that the results in Fig. 5 and 6 suggested that homocysteine incubated cardiomyocytes were less able to withstand an oxidative insult compared to controls. More pertinently, the smaller calcium transient (Fig. 4), faster time to exhibit contractile asynchronicity during oxidative stress (Fig. 6) combined with the compromised recovery of LVDP and RPP on reperfusion following ischaemia (Fig. 2a and 2b) and the lack of effect on time to ischaemic contracture (Fig. 3a) may suggest that under stressful conditions Hcy is more disruptive to the cardiomyocytes' ionic homeostasis than to their energy metabolism.

There was a significant decrease in the time to exhibit asynchronous contractile behaviour in the presence of $\mathrm{H}_{2} \mathrm{O}_{2}$ in homocysteine incubated cells compared to control (Fig. 6). This may be due to arrhythmic behaviour (such as delayed after-depolarisations) occurring secondarily to an increase in the action potential duration. This is consistent with studies conducted on isolated rat right ventricular papillary muscles and left atria that have shown that $0.1 \mathrm{mM}$ Hcy decreased the action potential amplitude; reduced the maximum velocity of the action potential upstroke and prolonged the action potential [13]. In separate electrophysiological studies conducted on isolated rat cardiomyocytes 0.05 and $0.5 \mathrm{mM}$ Hcy were shown to significantly reduce the maximum transient outward current, which is involved in repolarisation [14], and modulate sodium channel activity in isolated human atrial myocytes [12]. In addition to these studies investigating channels and currents it has also been shown that HHcy induced by Hcy feeding decreases cardiomyocyte contractility through activation of mitochondrial matrix metalloproteinase [25], whilst cardiomyocyte contractility was also reduced in HHcy resulting from targeted disruption of the cystathionine beta synthase gene [15].

It should be noted that isolated and perfused hearts exposed to ischaemia reperfusion is a different model to freshly isolated cardiomyocytes exposed to $\mathrm{H}_{2} \mathrm{O}_{2}$. The whole heart 


\section{Cellular Physiology Cell Physiol Biochem 2015;37:2265-2274 \begin{tabular}{ll|l} 
DOI: 10.1159/000438582 & $\begin{array}{l}\text { O } 2015 \text { The Author(s). Published by S. Karger AG, Basel } \\
\text { www.karger.com/cpb }\end{array}$
\end{tabular} \\ Almashhadany et al.: Homocysteine Impairs Stressed Myocardium}

for example contains connective tissue and vasculature, although it should be noted that homocysteine did not affect the coronary flow. There is also a difference in the timing of the oxidative burst that occurs transiently on reperfusion during ischaemia reperfusion compared to the longer term effect of continuous exposure to $\mathrm{H}_{2} \mathrm{O}_{2}$. There may also be a difference in the radical species involved with potentially more species involved in ischaemia reperfusion compared to the relatively specific model of $\mathrm{H}_{2} \mathrm{O}_{2}$. This may explain why LDH release during reperfusion was not affected by homocysteine (Fig. 3b), but cell viability during exposure to $\mathrm{H}_{2} \mathrm{O}_{2}$ and homocysteine was adversely affected (Fig. 5b).

Hcy on its own did not affect cardiac functional parameters before ischaemia (Fig. $2 \mathrm{a}$ and 2c). This contrasts with work carried out on rats given homocysteine thiolactone in their water, where diastolic function was compromised [26]. A possible reason for this discrepancy is the acute nature of the current study compared to the longer term of homocysteine treatment in the study by Mendes et al. [26]. Also the decrease in the numbers of cells displaying rod shaped morphology in the presence of Hcy with time was no worse than that occurring in the control (Fig. 5a). These results might suggest that in the current study it was only when Hcy exposure occurred in the presence of another stressor such as oxidative stress and/or ischaemia-reperfusion that the outcome is detrimental. The exception to this was the reduced calcium transient under normal conditions (Fig. 4). This could be due to Hcy affecting cellular contractility before morphology and viability or to the different conditions under which these cell experiments are conducted. In the case of measuring calcium transients the cells are stimulated, whilst in the cell morphology and viability experiments the cells are quiescent.

In conclusion exposure to $0.1 \mathrm{mM}$ homocysteine impairs subsequent functional recovery of the isolated and perfused heart during ischaemia reperfusion, compromises the contractility of freshly isolated cardiomyocytes during oxidative stress and reduces their calcium transient under normal conditions. A suggested mechanism for the pathogenic effects of homocysteine could involve the disruption of ionic homeostasis.

\section{Acknowledgments}

This work was supported by the British Heart Foundation [grant number PG/05/030], Kermanshah University and the University of New England.

\section{Disclosure Statement}

None declared.

\section{References}

1 WHO: Global status report on noncommunicable diseases 2010. World Health Organisation, Geneva 2011.

2 Antoniades C, Antonopoulos AS, Tousoulis D, Marinou K, Stefanadis C: Homocysteine and coronary atherosclerosis: from folate fortification to the recent trials. Eur Heart J 2009;30:6-15.

3 Selhub J: The many facets of hyperhomocysteinemia: studies from the Framingham cohorts. J Nutr 2006;136:1726S-1730S.

4 Refsum H, Ueland PM, Nygård O, Vollset SE: Homocysteine and cardiovascular disease. Ann Rev Med 1998;49:31-62.

5 Abraham JM, Cho L: The homocysteine hypothesis: still relevant to the prevention and treatment of cardiovascular disease. Cleveland Clin J Med 2010;77:911-918.

6 Balakumar P, Rohilla A, Singh G, Singh K, Singh M: Modulation of cardioprotective effect of ischemic pre- and postconditioning in the hyperhomocysteinemic rat heart. Met Findings Exptl Clin Pharmacol 2009;31:71-79. 


\section{Cellular Physiology Cell Physiol Biochem 2015;37:2265-2274

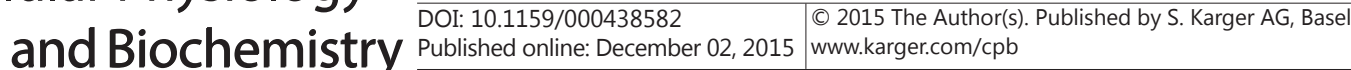 \\ Almashhadany et al.: Homocysteine Impairs Stressed Myocardium}

$7 \quad$ Xia M, Conley SM, Li G, Li P-L, Boini KM: Inhibition of hyperhomocysteinaemia induced inflammasome activation and glomerular sclerosis by NLRP3 deletion. Cell Physiol Biochem 2014;34:829-841.

8 Martí-Carvajal AJ, Solà I, Lathyris D, Karakitisiou DE, Simancas-Racines D: Homocysteine-lowering interventions for preventing cardiovascular events. Cochrane Database Sys Rev DOI:10.1002/14651858. CD006612.pub3.

9 Levrand S, Pacher P, Pesse B, Rolli J, Feihl F, Waeber B, Liaudet L: Homocysteine induces cell death in H9C2 cardiomyocytes through the generation of peroxynitrite. Biochem Biophys Res Comm 2007;359:445-450.

10 Sipkens JA, Krijnen PAJ, Meischl C, Cillessen SAGM, Smulders YM, Smith DEC: Homocysteine affects cardiomyocyte viability: concentration-dependent effects on reversible flip-flop, apoptosis and necrosis. Apoptosis 2007;12:1407-1418.

11 Zhao L, Wang G, Lu D, Wu J, Song F, Dong J, Bi Z, Li Y: Homocysteine, hRIP3 and congenital cardiovascular malformations. Anat Embryol 2006;211:203-212.

12 Cai B, Shan L, Gong D, Pan Z, Ai J, Xu C, Lu Y, Yang B: Homocysteine modulates sodium channel currents in human atrial myocytes. Toxicol 2009;256:201-206.

13 Pacher P, Ungvari Z, Kecskemeti V: Electrophysiological effects of homocysteine in isolated rat ventricular papillary muscles and left atria. Gen Pharmacol 1999;32:439-443.

14 Shontz RD, Xu Z, Patel KP, Rozanski GJ: Inhibition of K+ currents by homocysteine in rat ventricular myocytes. J Cardiovasc Electrophys 2001;12:175-182.

15 Wang X, Cui L, Joseph J, Jiang B, Pimental D, Handy DE, Liao R, Loscalzo J: Homocysteine induces cardiomyocyte dysfunction and apoptosis through p38 MAPK-mediated increase in oxidant stress. J Mol Cell Cardiol 2012;52:753-760.

16 Rohilla A, Singh G, Singh M, Kumar PB: Possible involvement of PKC- $\delta$ in the abrogated cardioprotective potential of ischemic preconditioning in hyperhomocysteinemic rat hearts. Biomed Pharmacother 2010;64:195-202.

17 Dayal S, Blokhin OI, Erger RA, Jensen M, Arning E, Stevens JW, Bottiglieri T, Faraci FM, Lentz SR: Protective vascular and cardiac effects of inducible nitric oxide synthase in mice with hyperhomocysteinemia. Plos One 2014;9:e107734.

18 Shackebaei D, Kayhani B, Godini A, Pourshanazari A, Reshadat S: The effect of repeated diazepam administration on myocardial function in the ischemia reperfusion isolated rat heart. Saudi Med J 2009;30:755-759.

19 Shackebaei D, King N, Shukla B, Suleiman M-S: Mechanisms underlying the cardioprotective effect of L-cysteine. Mol Cell Biochem 2005;277:27-31.

20 King N, McGivan JD, Griffiths EJ, Halestrap AP, Suleiman M-S: Glutamate loading protects freshly isolated and perfused adult rat cardiomyocytes from intercellular ROS generation. J Mol Cell Cardiol 2003;35:975984.

21 King N, Lin H, Suleiman M-S: Cysteine protects freshly isolated cardiomyocytes against oxidative stress by stimulating glutathione peroxidase. Mol Cell Biochem 2010;343:135-142.

22 Shi Y-F, Liu N, Li Y-X, Song C-L, Song X-J, Zhao Z, Liu B: Insulin protects H9c2 rat cardiomyoblast cells against hydrogen peroxide-induced injury through upregulation of microRNA-210. Free Rad Res 2015;49:1147-1155.

23 Gopinath B, Flood VM, Rochtchina E, Thiagalingam A, Mitchell P: Serum homocysteine and folate but not vitamin B12 are predictors of CHD mortality in older adults. Eur J Prevent Cardiol 2012;19:1420-1429.

24 Kroll K, Martin GV: Comparison of myocardial ATP, blood flow, and cytosolic adenosine in demand ischemia and coronary occlusion. Am J Physiol 1995;269:H819-H828.

25 Moshal KS, Tipparaju SM, Vacek TP, Kumar M, Singh M, Frank IE, Patibandla PK, Tyagi N, Rai J, Metreveli N, Rodriguez WE, Tseng MT, Tyagi SC: Mitochondrial matrix metalloproteinase activation decreases myocyte contractility in hyperhomocysteinemia. Am J Physiol 2008;295:H890-H897.

26 Mendes RH, Sirvente RA, Candido GO, Mostarda C, Salemi VMC, D’Almeida V, Jacob MH, Ribiero MF, BelloKlein A, Rigatto K, Irigoyen MC: Homocysteine thiolactone induces cardiac dysfunction: Role of oxidative stress. J Cardiovasc Pharmacol 2010;55:198-202. 